\title{
IDENTIDADE LINGUISTICA: DEBATE DAS POLITICAS EDUCATIVAS EM ANGOLA
}

\author{
Eduardo David T. Ndombele ${ }^{1}$
}

\begin{abstract}
Resumo: Este artigo traz uma reflexão sobre o lugar que as línguas africanas de origem bantu ocupam na construção das políticas educativas em Angola, 40 anos após a conquista da independência Nacional. Considerando as políticas educativas, como conjunto de medidas planejadas por um Governo, no sentido de se determinar o que é possível fazer, neste caso no domínio da educação, ou seja, o que deve ser incorporado ou excluído na (re) definição da agenda para a educação em consonância com esse entendimento. Neste estudo, primeiramente, foi feito um levantamento da política educativa da administração colonial para, na sequência, fazer uma análise da política educativa vigente em Angola. Para se atingir os fins propostos, o método de trabalho escolhido foi o documental e bibliográfico.
\end{abstract}

Palavras-chave:Angola, identidade linguística, Políticas educativas, educação.

\section{IDENTITE LINGUISTIQUE: POLITIQUES EDUCATIVES EN ANGOLA}

Resumé: Cet article présente une réflexion sur la place des langues africaines dans le processus d'enseignement et apprentissage, 40 ans aprés la conquete de l'independance nationale. Sachant que la politique éducative est l'ensemble de mesures envisagées par le gouvernement, afin de déterminer ce qui est possible dans ce cas dans le domaine de l'éducation, qui est, qui devrait être incorporé ou supprimé dans le programme. Dans cette perspective nous avons jugé important de peindre d'abord un petit panorama sur la politique éducative de l'administration coloniale et après la politique éducative actuelle en Angola. Pour atteindre les objectifs proposés, nous avons choisie la méthode documentaire et bibliographique.

Mots clés: Angola, identité linguistique, Politiques educatives, education.

\footnotetext{
${ }^{1}$ Doutor em Linguística, docente afecto ao Departamento de Letras Modernas do Instituto Superior de Ciências de Educação do Uíge (Angola). Email: david.eduardo73@gmail.com
} 


\title{
Introdução
}

Angola foi, durante cerca de 5 séculos, colónia portuguesa e conquistou a sua independência a 11 de Novembro de 1975. País está a passar por uma fase de reconstrução e desenvolvimento em todos os sectores desde 2002, um dos principais desafios com que se depara é o da educação, fragilizado por cerca de 27 anos de guerra fratricida. Entretanto, tem sido preocupação do Estado angolano através do Ministério da Educação, traçar estratégias que visem orientar, acompanhar e executar a política do Executivo relativa à educação.

\begin{abstract}
A chegada dos portugueses em Angola ocorreu por ocasião das viagens do português Vasco da Gama pelo do Oceano Atlântico para descobrir as Índias. Foi assim que no século XV, mais propriamente em 1482, quando o navegador Diogo Cão aportou na foz do Rio Zaire, que se estabeleceram os primeiros contactos entre os africanos do Reino do Kongo (Angola) e europeus vindos de Portugal No início desse encontro de civilizações os portugueses disfarçaram-se em atitudes de cooperação; no entanto, os fatos que se seguiram demonstraram que eles buscavam o domínio sobre os angolanos a qualquer custo (SOUSA, 2015, p. 21).
\end{abstract}

Portugal foi a primeira potência colonizadora europeia no continente africano e a última a deixá-lo. 500 anos ad infinitum, caso de (Angola)

Na esteira da presença de administração colonial, foi instituída em Angola em uma estrutura oficial do ensino, pelo decreto de 14 de Agosto de 1845, criado por Joaquim José Falcão, Ministro do Estado, da Marinha e do Ultramar, e assinado pela rainha D. Maria II. Falcão criou algumas escolas, tal como a Escola Principal de Instrução Primária, e constituiu um Conselho Inspector de Instrução Pública.

Esse primeiro passo, apesar de importante, não foi contudo suficiente, uma vez que as populações não estavam motivadas nem tão pouco preparadas para a frequência escolar, sendo por isso necessário dar tempo a que as medidas se consolidassem. Para dar novo impulso à educação, dez anos 
depois, Sá da Bandeira, ministro da Guerra e dos Negócios Estrangeiros, subscreveu uma portaria régia (datada de 19 de Novembro de 1856) que determinou que "os filhos dos régulos, sobas e outros potentados indígenas deveriam ser educados em Luanda, sob a orientação e vigilância das autoridades portuguesas, a expensas do Estado" (SANTOS, 1970, p. 134 apud LIBERATO, 2014).

Como manifestação das políticas educativas de Portugal o então Capitão Norton de Matos olhava a instrução no seio dos angolanos (autóctones) como meio de civilização, utilizando para o efeito a língua portuguesa, ou seja, ficando proibido o uso de qualquer língua bantu de origem angolana no nosso território (Angola). Defendia, de igual modo, a separação da educação ministrada aos africanos daquela ministrada aos portugueses. Para o indígena, a instrução literária limitava-se somente a: falar, ler e escrever o português, as quatro operações aritméticas e o conhecimento da moeda corrente de Angola. Simples palestras sobre higiene das pessoas e das habitações, contra os vícios e práticas nocivas, usos e costumes nefastos das vidas dos indígenas sobre a história de Portugal e os benefícios da civilização portuguesa adequadas às idades e ao desenvolvimento intelectual dos ouvintes, serão frequentemente feitas. (MATOS, 1926 apud ZAU, 2005).

A política educativa de Norton de Matos centrava-se num egocentrismo excessivo ao ponto de colocar uma linha divisória entre os indígenas e os não indígenas isto é o ensino para os indígenas ocorria, principalmente, em escolas rurais e escolas-oficinas, ambas mais direccionadas para o trabalho manual e para a aprendizagem de um ofício, do que para o desenvolvimento multifacetado das crianças de origem africana. Já o ensino para os não-indigenas, realizado em escolas infantis e em escolas primárias, "visava dar à criança os instrumentos fundamentais de todo o saber e as bases de uma cultura geral, preparando-a para a vida social". Como constatar nestes artigos elucidativos:

\footnotetext{
- Artigo 10: O ensino indígena tem por fim conduzir gradualmente o indígena da vida selvagem para a vida civilizada, formar-lhe a consciência de cidadão português e prepará-lo para a luta da vida, tornando-se mais útil à sociedade e a si próprio.
} 
- Artigo 7o: O ensino primário rudimentar destina-se a civilizar e nacionalizar os indígenas das colónias, difundindo entre eles a língua e os costumes portugueses (MAZULA, 1955 apud ZAU, 2005).

\section{Politicas Linguísticas de Norton de Matos}

“Como governador-geral, Norton de Matos é afigura por excelência do colonialismo português, incontornável pela modernidade que ele significa para aquela época. As suas realizações e os seus projectos não só o tornaram um mito ainda presente nos pós independência, como uma boa parte das infra- estruturas que deixou sobreviveram, mesmo se abaladas a quarenta anos de guerra". (DÁSKALOS, 2008, p. 19)

Administração colonial antes de 1975 aplicou um processo de aculturação que provocou a destruição em larga escala das estruturas económicas e sociais dos povos colonizados através de um processo organizado com decretos e leis. A título de exemplo decreto n. 977 de 1921:

Artigo 1.o, ponto 3: É obrigatório em qualquer missão, o ensino da língua portuguesa; Ponto 4: é vedado o ensino de qualquer língua estrangeira; Artigo 2.o: Não é permitido Ensinar nas escolas de missões línguas indígenas; Artigo 3. -: O uso de língua indígena só é permitido em linguagem falada na catequese e, como auxiliar, no período do ensino elementar da língua portuguesa; Parágrafo 1.o: É vedado na catequese das missões, nas escolas e em quaisquer relações com indígenas o emprego das línguas indígenas por escrito ou faladas de outras línguas que não sejam o português por meio dos folhetos, jornais, folhas avulsas e quaisquer manuscritos; Parágrafo 2. o: Os livros de ensino religioso não são permitidos noutra língua que não seja o português, podendo ser acompanhado do texto de uma versão paralela em língua indígena; Parágrafo 3. ․: O emprego da língua falada a que se refere o corpo deste artigo e o da versão em língua indígena, nos termos do parágrafo anterior, só são permitidos transitoriamente e enquanto se não generaliza entre os indígenas o conhecimento da língua portuguesa, cabendo aos missionários substituir sucessivamente e o mais possível em todas as relações com os indígenas e na catequese as línguas indígenas pela língua portuguesa; Artigo 4. o: As disposições dos dois artigos antecedentes não impedem os trabalhos linguísticos ou quaisquer outros de 
investigações científicas, reservando-se, porém, ao governo, o direito de proibir a sua circulação quando, mediante inquérito administrativo, se reconhecer que ela pode prejudicar a ordem pública e a liberdade ou a segurança dos cidadãos e das populações indígenas [Decreto $\mathrm{n}$. . 77/21].

Como consequência desta política glotofagica, Angola mesmo após a proclamação da sua independência em 1975 adoptou o português como língua oficial, uma escolha que terá sido motivada por razões diversas, uma delas é a falta de uma planificação linguística.

Já no reino do Ndongo os portugueses encontraram uma resistência ao tentarem aplicar a sua política de assimilação total e desintegração da identidade africana, onde a rainha Nzinga Mbandi tinha escrito, em Fevereiro de 1629, uma carta, da qual extraímos algumas passagens:

Ao vosso Governador, Sr Fernão de Sousa. Ide dar-lhe este meu recado. E dizei-lhe também que o nome de Ana de Sousa que o outro me quis oferecer não pegou.Nao podia pegar. O mesmo sucede com as minhas irmãs, a Kambo não quer o nome de Barbara, a Fuxi manda dizer que o seu nome é mesmo Fuxi. Que ide aplicando o nome de Engrácia as vossas filhas que is parindo vós outros. Mau grado os esforços todos meus para um possível conciliação entre vós e nós, entre as nossas coisas e as vossas. (KUKANDA,1988, p. 56)

NZinga Mbandi, Dizonda, como ela mesma assinava os documentos. Organizou formidável coligação política sob sua égide. Apoiada numa coalizão reunindo os reinos da Matamba, Ndongo, Congo, Kassanje, Dembos e Kissama, a rainha combateu sem tréguas a invasão portuguesa. Resistiu até os últimos dias de sua vida sem jamais ter sido capturada. (WALDMAN, 2013).

Neste contexto, a nova Reforma Educativa em vigor em Angola demonstrou a necessidades premente de um reajuste no domínio das políticas linguísticas da educação, criando assim algumas bases necessárias para a inserção das línguas nacionais em todos sub- sistemas de ensino. Sendo línguas de características regionais seriam escolarizadas nas respectivas 
zonas de influência, nomeadamente Kimbundu, Umbundu, Kikongo, Côkwe, Nganguela, Oshykwanyama e Fyote.

Conhecidos que são alguns propósitos das políticas educativas da administração colonial, que se foi estendendo de acordo com os interesses da própria administração colonial, até em 1975, passamos a abordar as inovações da política educativa do Estado angolano com o Presidente Agostinho Neto.

\section{Novo sistema de ensino em Angola (1977)}

Após a proclamação da independência Nacional em Novembro de 1975, inaugurava-se uma nova era na história de Angola. O novo governo formado sob a direcção do MPLA, com uma orientação eminentemente socialista, tratou de empreender mudanças profundas no seu funcionamento. No período posterior à independência. OMPLA, como único representante do povo angolano, lançou bases para a consolidação do novo Estado dirigido por um sistema político de partido único.

Em 1977, dois anos após a independência, foi adoptado um novo Sistema de Educação e Ensino (SEE), que veio a ser implementado, a partir de 1978.

É nesta sequência de ideais que, segundo Zau,

O Partido no Poder, MPLA-PT (Movimento Popular de Libertação de Angola-Partido do Trabalho) apresentou nas suas «teses e resoluções» do seu 1 Congresso sobre a educação em 1977 Algumas premissas para a constituição do sistema de educação e ensino na República Popular de Angola, a saber: A herança pré-colonial; A herança de Angola colonizada; As experiências educacionais durante o processo das duas guerras consecutivas de libertação; Conquista do poder político pelo MPLA, a instalação de consolidação do Poder Popular; Os esforços empreendidos no sentido de transformações revolucionárias no sistema político económico e sócio cultural na República Popular de Angola, depois do 11 de Novembro de 1975; e O desenvolvimento moderno e contínuo da ciência e da técnica no Mundo e na R.P.A., a 
sua influência no modo de vida das pessoas em geral e em particular no acesso irreversível e cada vez maior, que as grandes camadas da população angolana devem ter, em relação às conquistas e riquezas educativo-culturais (isto é, os camponeses, operários e outros elementos deles dependentes economicamente, que constituem as camadas mais exploradas e a maioria esmagadora da população angolana). (apud ERNESTO, 2016, p. 22)

Com isto, estavam traçadas todas primícias para a implementação, em 1978 do primeiro sistema de ensino em Angola de pois de 500 anos de colonização por três subsistemas, a saber: O Subsistema de Ensino Geral; O Subsistema de Ensino Técnico-profissional; O Subsistema de Ensino Superior.

O maior impacto tangível do novo sistema de educação constitui numa explosão escolar que se traduziu na grande afluência da população às escolas, pois se em 1974 estudavam cerca de meio milhão de angolanos, em 1980 esse número era já superior a 1,8 milhões (INIDE, 2003).

O Ministério da Educação e Cultura (MEC) subdividiu-se em Ministério da Educação (MED) e Conselho Nacional de Cultura (CNC), sendo, este último, dirigido por um secretário de Estado. (Leis no 72/76 e no 73/76 de 23 de Novembro). O poeta António Jacinto do Amaral Martins foi o primeiro titular da pasta do Ministério da Educação e Cultura (MEC). Posteriormente, após a reformulação do aparelho do Estado, Ambrósio Lukoki passou a ser o ministro da Educação, coadjuvado por Artur Pestana "Pepetela", como viceministro.

Posteriormente, através do decreto no 9/87, de 30 de Maio, do Conselho de Ministros, foi aprovado um novo Estatuto Orgânico do Ministério da Educação, passando a existir, na direcção do MED, mais um vice-ministro. As escolas do I nível do Ensino de Base Regular passavam a depender, administrativamente e a nível local, das Delegações Provinciais de Educação (DPE) e, a nível central, metodologicamente, da Direcção Nacional do Ensino Geral (DNEBR).

A Direcção de Formação de Quadros de Ensino (DNFQE) continuaria a assegurar a formação e a elevação do nível cultural e profissional dos 
docentes. Estas duas Direcções Nacionais passariam a ser coordenadas e supervisionadas através de um mesmo vice-ministro da Educação. Augusto Lopes Teixeira assumia a titularidade do sector, coadjuvado pelos viceministros Joaquim Matias, para o Ensino Geral e Artur Pestana "Pepetela", para o Ensino Médio e Superior (cf ZAU, 2005).

A matriz do SEE em Angola no pós-independência era constituída por várias instituições educativas. Na base do sistema estão as Instituições para a Educação Pré-Escolar. As mesmas estavam a cargo da ex-Secretaria de Estado dos Assuntos Sociais (SEAS), que velava pelos Centros Infantis, que deviam receber crianças matriculadas em creches (até aos 3 anos) e em jardins infantis (dos 3 aos 6 anos). Posteriormente, dos 5 aos 6 anos, as crianças entrariam na classe de Iniciação.

As Escolas do Ensino de Base são o alicerce do sistema educacional, onde o ensino, obrigatório e gratuito, se destina a crianças dos 6 aos 14 anos de idade. Como factor de identidade, as escolas do Ensino de Base procuravam dar a cada jovem cidadão os elementos iniciais da educação socialista e a instrução geral moderna.

Os Institutos do Ensino Médio apresentavam carácter especializado e englobam as instituições que se ocupam do Ensino Médio Profissional. Já as Escolas do Ensino Superior, teoricamente constituídas por Institutos Superiores e Academias de Belas-Artes, seriam instituições frequentadas por candidatos que tivessem completado um dos Institutos do Ensino Médio. Para além destas instituições, a matriz do sistema educativo angolano refere-se ainda às Instituições para a Educação dos Adultos e Aperfeiçoamento Profissional, que deveriam zelar pela educação e profissionalização de adultos sem escolarização básica e sem preparação para a actividade laboral. As Escolas Especiais e outros estabelecimentos de ensino, que se destinariam a crianças e jovens deficientes, com o propósito de torná-las capazes para a vida autónoma e laboral. 


\section{Estrutura do sistema de ensino}

\section{Ensino Primário}

O Ensino Primário tinha 4 anos de duração abarcando:no caso do Ensino de Base, - a 1aㅡ, a 2aa a $3^{2}$ e a $4^{a}$ classes, constituindo o $1^{\circ}$ nível do Ensino de Base Regular, e, a Alfabetização e a Pós-Alfabetização constituindo o 1o nível do Ensino de Adultos.

\section{1 ciclo do Ensino Secundário}

O Ensino Secundário 1ำ ciclo compreendia 4 anos de duração abarcando: no caso do Ensino de Base, a $5^{\underline{a}}$ e a $6^{a}$ classes que constituíam o $2^{\circ}$ 은 nível do Ensino de Base Regular e da Educação de Adultos, e, a 7a e a $8^{a}$ classes que constituíam o 3o nível do Ensino de Base Regular e da Educação de Adultos; no caso da Formação Profissional, a 5a e a 6a classes que constituem o 1 을 ciclo de Trabalhadores Qualificados (1ำ ciclo da Formação Profissional) e, a 7 a e a $8^{\text {a }}$ classes que constituem o $2^{\circ}$ ciclo de Trabalhadores Qualificados ( 1 은 ciclo da Formação Profissional).

\section{2ำ Ciclo do Ensino Secundário}

O 2ำ ciclo do Ensino Secundário tinha 3 ou 4 anos de duração do Ensino Pré-Universitário e Médio, abarcando:no caso de Ensino PréUniversitárioo 1으, o 2o e o 3o ano, no caso do Ensino Médio Normala 9aㅗ a 10aa a 11a e a $12^{a}$ classe, e no caso do Ensino Médio Técnico a 9aㅡ, a $10^{a}$, a $11^{\underline{a}}$ e a $12^{\underline{a}}$ classes.

\section{Ensino Superior}

O Ensino Superior tinha 5 anos de duração repartidos em 2 níveis, sendo: o 1으, o 2o e o 3 o ano do 1o nível, sem carácter terminal, eo 4으 e o 5o anos do 2 nível. O ingresso para e Ensino Superior é possível após 11 anos de escolaridade, concluindo um curso pré-universitário com 3 anos de duração 
na sequência dos 8 anos do Ensino de Base. O mesmo é possível ainda após 12 anos de escolaridade, concluindo um curso médio normal ou técnico com 4 anos de duração na sequência dos 8 anos do Ensino de base.

O Estado angolano criou a primeira universidade de Angola, por força da resolução n: 01/85 do Conselho de Defesa e Segurança publicado no Diário da República n: 09 1a Série, 28/1/1985, que passou a chamar-se Universidade Agostinho Neto (UAN), em memória do primeiro Presidente de Angola Dr. António Agostinho Neto (cf. GINGONGO, 2014).

\section{Formação de Professores}

Não sendo inicialmente um subsistema, a Estrutura a Formação de Professores tinha como objectivo assegurar o desenvolvimento do SEE ao nível básico, médio e profissional. A vertente da Formação Regular contava com os Institutos Normais de Educação (INE), também mais tarde designados por Institutos Médios Normais (IMN), que deveriam formar professores para exercerem a sua actividade docente no Ensino de Base, no I nível, ou em disciplinas da especialidade, no II e no III nível. Nos INE eram também diplomados, ao nível médio, os educadores de infância, para as instituições da Educação Pré-Escolar.

O Instituto Superior de Ciências da Educação (ISCED), no âmbito da formação de formadores, passava a garantir o funcionamento da formação de professores para os Institutos Médios. A finalidade essencial é de formar professores para todos os níveis de ensino e, em especial, para o ensino médio. O diploma legal da sua criação atribuía-lhe também como tarefas a reciclagem dos quadros e especialistas do Ministério da Educação e a investigação científica para desenvolver o sector da educação.

O Instituto Superior de Ciências de Educação em sigla ISCED, veio cobrir um lugar primordial no sistema de formação de professores por servir de elemento reprodutor da formação, ou seja, a sua vocação é a formação de formadores. Aos professores aqui formados cabe a função de formar outros formadores. 


\section{A nova reforma nas políticas educativas de Angola}

O processo de nova reformaeducativa encontra-sena lei 13/01 de 31 de Dezembro é a lei de base do sistema educativo que prevê a formação de cidadãos motivados e capazes de intervir activamente e eficientemente na realidade que os cerca.

Em Angola foi implementado esta lei com o objectivo principal da melhoria da qualidade de ensino através de alterações dos programas, da qualificação de currículos de ensino, reclassificação dos agentes de educação.

A actual reforma educativa foi antecedida pelo um período chamado de diagnóstico no sistema de educação em 1986, etapa de diagnóstico do antigo sistema de educação que foi realizada de Março a Junho de1986;

Em 2001, a Assembleia Nacional da República de Angolaaprovou a Lei de Bases do Sistema Educativo (Lei 13/ 01 de 31 de Dezembro). Este documento contém o esboço do que se pretende com esta acção e define o novo sistema, cuja estrutura integra os seguintes subsistemas: Subsistema da Educação Pré - Escolar; Subsistema do Ensino Geral; Subsistema do Ensino Técnico - Profissional; Subsistema da Formação de Professores; Subsistema da Educação de Adultos; e Subsistema do Ensino Superior.

A primeira fase começou em 2002, onde houve a criação das condições indispensáveis para poder assegurar o seu normal funcionamento nomeadamente a adequação dos sistemas de administração e gestão em nível central e local.

A segunda fase teve início em 2003 e foi feita a experimentação dos novos currículos escolares, planos de estudos, programas e matérias pedagógicas.

A terceira fase começou em 2006, onde se dedicou a avaliação e correcção, com base nos dados que foram sendo recolhidos na fase experimental.

A quarta fase, decorreu de 2006 a 2011 e foi feita a introdução progressiva da reforma educativa nos vários anos de ensino, que culminou com a extinção do actual sistema educativo que integra o ensino primário, secundário, médio e superior. 
A quinta fase da reforma educativa decorreu entre 2012 e 2015 dedicada à avaliação do novo sistema.

A reforma do sistema educativo, aprovada pela lei 13/01 de 31 de Dezembro, incluiu novas divisões dos níveis de ensino, alterações nosistema de avaliação dos alunos, criação de novas cadeiras e reformulação de conteúdos curricular.

\section{Sistema de avaliações de aprendizagem no quadro da nova reforma}

No quadro da avaliação das aprendizagens vigente a luz da reforma educativa a escala de avaliação numérica para todas as disciplinas vária de zero a vinte valores. A mesma escala é subdividida, por forma a traduzir os níveis de cumprimento dos objectivos de todas as disciplinas, nos escalões seguintes:

$$
\begin{aligned}
& \text { De } 0 \text { a } 4 \text { - Mau, o aluno aqui progride pouco; } \\
& \text { De } 5 \text { a } 9 \text { - Medíocre, o aluno aqui progride lentamente; } \\
& \text { De } 10 \text { a } 13 \text { - Suficiente, o aluno aqui progride bem; } \\
& \text { De } 14 \text { a } 17 \text { - Bom, aqui o aluno progride bem;e } \\
& \text { De } 18 \text { a } 20 \text { - Muito bom, o aluno progride com segurança. }
\end{aligned}
$$

No final da $10^{\mathrm{a}}, 11^{\mathrm{a}}, 12^{\mathrm{a}}$ e $13^{\mathrm{a}}$ classe, o aluno transita de calasse se obtiver classificação final igual ou superior a DEZ (10) valores em todas as disciplinas.

No final da 13a classe o aluno só transita de classe desde que obtenha classificação igual ou superior a DEZ (10) valores em todas as disciplinas incluindo o exame de aptidão profissional. O exame de aptidão profissional destina-se aos alunos da 13a classe.

\section{O lugar das Línguas africanas (Línguas nacionais) no sistema de Ensino}

A complexidade da situação sociolinguística de Angola inspira cuidados redobrados quando a questão é o ensino das línguas africanas de 
origem bantu: Por estarem ainda limitado o seu ensino na maioria das escolas do País. Desde 1976 até à actualidade a língua portuguesa é a língua oficial, de escolaridade e de comunicação internacional.

A língua é produto da sociedade, e é de per se um veículo de acesso à informação e à formação escolar e extra-escolar.

Sabe-se que Angola é caracterizado como um país multilingue, sendo assim apresenta uma heterogeneidade linguística do norte ao sul .Angola, ao longo de muitos anos enfrentou problemas relacionados com uma diglossia de português em todos sub-sistemas de ensino. A reforma em curso recomenda fortemente a inserção das línguas nacionais no processo de ensino e aprendizagem de acordo com a língua de cada região.

Sabe-se também, que a maioria das crianças angolanas das zonas rurais entram na escola sem ter conhecimentos da língua portuguesa e consequentemente tem problemas para entender as aulas ministradas por parte de professores.

Por estas razões alguns linguistas e didácticos têm pesquisado sobre a influência da língua materna na aprendizagem da língua segunda e tem apontado as seguintes causas:

a) As crianças não tem oportunidade de ler e escrever na sua língua materna

b) O processo de ensino e aprendizagem é desenvolvido na língua portuguesa, caso de Angola, que é basicamente uma língua estranha para a maioria dos alunos das zonas rurais.

c) Falta de motivação por parte das crianças que dominam as línguas africanas.

A pedagogia defende, que as crianças aprendem e desenvolvem bem as suas habilidades, se a aula for ministrada na sua língua materna. E nós pensamos que a inserção efectiva das línguas nacionais no sistema de ensino em Angola, poderá trazer resultados positivos para as crianças, no processo de aprendizagem e isto não será apenas profícuo para as crianças, mas também para o conjunto de línguas angolanas, no sentido de elas deixarem de ser 
marginalizadas e passarão a ser vistas como línguas de identidade e de afirmação de valores culturais.

Todavia, o uso e não uso de uma língua materna no sistema de ensino numa Nação depende inteiramente das políticas linguísticas adoptadas pelo Estado.

Nós advogamos por uma educação bilingue em Angola, como sendo um processo de ensino e aprendizagem que inicia com a língua materna no caso língua nacional de uma determinada região dos alunos, com uma transição gradual para a língua segunda no caso a língua portuguesa.

Pensamos nós ainda, um dos, objectivos da educação bilingue é olhar para a criança como centro do processo educativo que utilize duas línguas como meio de instrução em parte ou em todo currículo.

\section{Considerações finais}

O Sistema de Educação e Ensino em Angola foi marcado por duas grandes reformas: A primeira aconteceu em 1977 dois anos depois da conquista de independência nacional e a segunda em 2002, resultante de aprovação pela Assembleia Nacional da Lei 13 de 2001.

A primeira reforma aconteceu em 1977/78, a mesma foi caracterizada por uma maior oportunidade de acesso à educação, centrada emprincípios de gratuidade alargada no ensino e nos princípios de igualdadede oportunidade no acesso à escola e à continuação dos estudos de forma gratuita

Já na segunda reforma a Lei de bases abrange as directrizes que estabelecem de um modo geral as mudanças do sistemaeducativo do país, reúne toda a organização e funcionamento normativo de um processo educacional.

A segunda reforma traz como novidades: Extensão da Monodocência para a 5. a e 6. a classe. Na monodocênciaa resposanbilidade recai a um só individuo, o Professor, em muitos casos os ditos professores não se sentem preparados para lecionar todas disciplinas. 
Seria a monodocência uma opção certa ou precipitada face a Polidocência?

A reforma educativa de 1997 não conseguiu resolver a problemática da língua de escolaridade em todos sub sistemas de ensino.Existindo várias línguas nacionais de origem angolana preocupou - nos em saber como as crianças com dificuldade na língua oficial assimilam os conteúdos, já que a lei de bases do sistema de educação no seu artigo 9 no ponto 1ํ diz que “ O ensino nas escolas é ministrado em língua oficial portuguesa".

Verifica-se que de Cabinda ao Cunene o português continua a ser usado como a única língua de ensino.

Ao fazermos a análise ao artigo 9o da Lei de Bases do Sistema de Ensino (LBSE), limitaseriamente o direito das crianças menores de 18 anos fundamentalmente os das zonas rurais em não aprender a ler e escrever nas suas línguas nativa por sinal línguas maternas dos seus pais e como consequência desta tendência tudo aquilo que se associa a estas línguas tem um sentido pejorativo e até mesmo aquilo que se encontra ligado ao seu património cultural.

\section{Referências}

ASSEMBLEIA NACIONAL. Decreto no 2/05 de 14 de Janeiro. Plano de implementação progressivo do novo Sistema de Educação. Luanda: Imprensa Nacional. n. 6, 2004.

CONSELHO DE MINISTROS. Estratégia Integrada para a Melhoria do Sistema de Educação 2001/2015. República de Angola, 2001.

DSKALOS, Maria. A política de Norton de Matos para Angola-1912-1915. Coimbra, Edições Minerva, 2008.

DEMO. Pedro. Desafios Modernos da Educação. 12. ed. Petrópolis: Vozes. 2002.

ERNERTO Eliseu, Terminologia da Reforma Educativa (2001-2014) Proposta de uma Base de Dados Terminológica para o Ministério da Educação de Angola. Dissertação de Mestrado Universidade Nova de Lisboa, 2016. 
GINGONGO, Vicentino. O Impacto da insuficiência de docentes no Instituto Superior de ciências de Educação do Uíge. Lisboa: Publidisa, 2014.

KUKANDA,Vatome. Introdução à sociolinguística. Lubango: CDI, 1988.

MINISTÉRIO DA EDUCAÇÃO. Plano Nacional de Capacitação de Professores do Ensino Primário, Luanda: INIDE editora, 2005.

INIDE. Programa da Reforma Educativa do Ensino Primário, $1^{\underline{a}}$ e $2^{\underline{a}}$ Classes. Luanda, 2005.

SOUSA Ngangula. Ensino superior em Angola: uma perspectiva histórica. Dissertação de Mestrado universidade de Paraná, 2015, Brasil.

WALDMAN, Maurício. A memória viva da rainha Nzinga: identidade, imaginário e resistência. Jornal ecos de Angola, 2013.

ZAU, Filipe. O Professor do Ensino Primário e o Desenvolvimento dos Recursos Humanos em Angola (uma visão prospectiva)Tese de doutoramento. Universidade aberta, Portugal, 2005.

Recebido em 1 de novembro de 2016.

Aceito em 11 de dezembro de 2016. 